\section{Setting their Table: Women and the Periodic Table of Elements}

\section{Murcia, Spain, 11-12 February 2019}

In the history of the discovery and establishment of the Periodic Table, it seems there are hardly any women scientists involved. However, they are more numerous when it comes to filling the table, and discovering elements, their properties, and their use. Unfortunately, even those women are often forgotten or overlooked. This symposium will specifically address the contribution of women to the Periodic Table and the knowledge of its elements, by demonstrating the presence of women and girls in the history of the development and filling of the PT, by reviewing the present situation and achievement of women in chemistry today and setting the table for the future.

The symposium is organized under the auspices of UNESCO and through the cooperation of IUPAC, IUHPST, EuChemS (European Chemical Society) as well as the Real Sociedad Española de Química and the University of Murcia. This international conference is set against the backdrop of the International Year of the Periodic Table of the Elements and will start on the International Day for Women and Girls in Science. The program includes plenary lectures, key notes, oral communications and posters, and a round table.

\section{Scientific Topics}

While the Periodic Table has been established for a while now, and the number of available elements is finite, the progress of chemistry continues to enable researchers to find new ways to use these elements for the benefit of men and women, and meet the challenges faced by humanity in the 21st century. The focus of this symposium is on the contribution of women, and how these contributions have been implemented by the scientific community.

The Symposium sessions will cover a variety of advanced topics on following subjects:

- history of women, the elements and the Periodic Table

- the Periodic Table and chemical education, past, present and future (with a special attention to secondary school teachers and pedagogy)

- the elements and the Periodic Table for sustainable chemistry

- beyond the elements: building nano- and biomaterials

- old elements, new technologies: how to improve the quality of life

- women in the chemical sciences, engineering and technologies

- endangered elements: how to face the scarcity of resources

For more information on the symposium, the venue, the associated events and how to register, see the website: http://www.ivpt2019women.es/ or send an email to <congresos@verticesur.es>

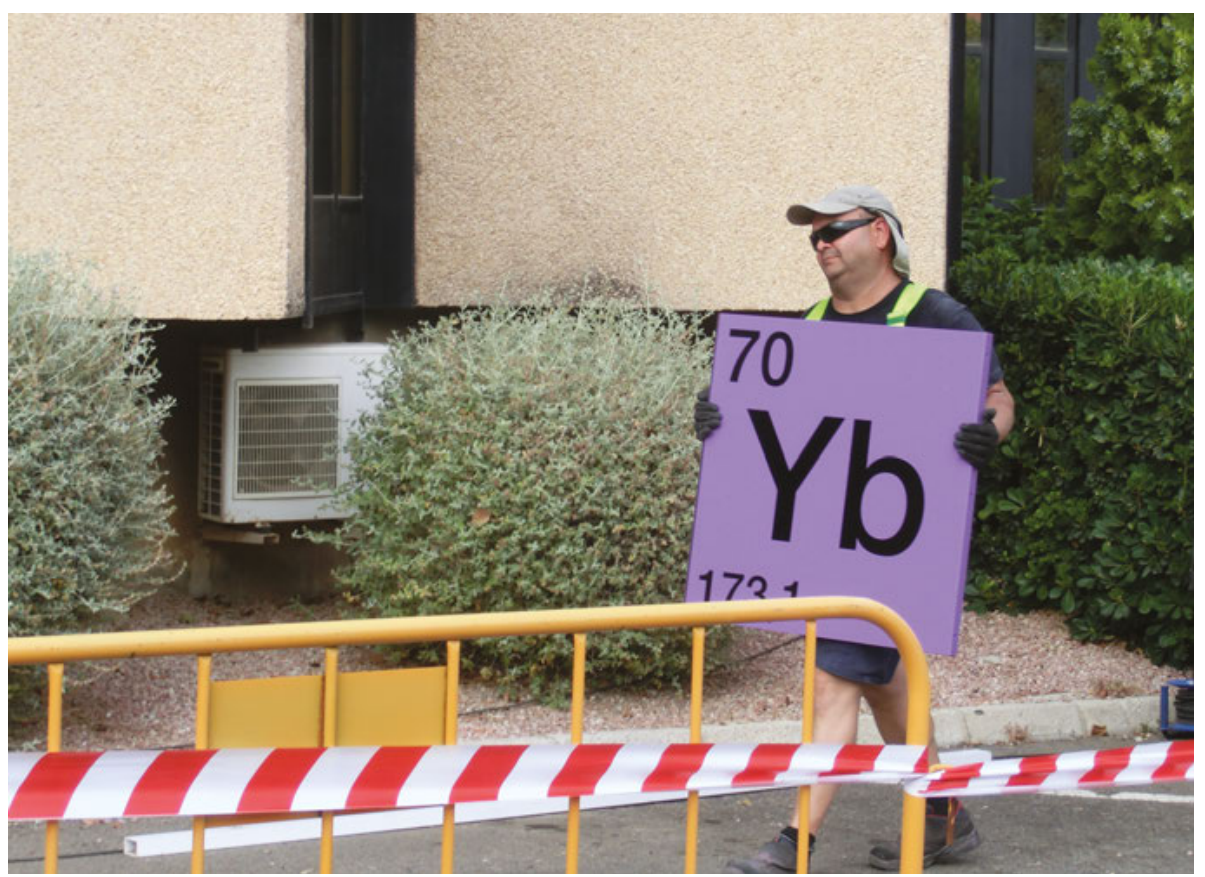

For the installation in 2017 of the most likely largest mural Periodic Table (see this $\mathrm{Cl}$ issue cover), $11875 \times 75 \mathrm{~cm}$ metal squares were fastened on the facade of the chemistry building at the University of Murcia, Spain, representing all the known elements and covering approximately $150 \mathrm{~m}^{2}$ in total. This was hard work. In February 2019, Murcia will be the site of IYPT2019 event reflecting on the contribution of women to the Periodic Table and the knowledge of its elements. 